\title{
Elephants in a Room of Our Own: Scientists, Humanists; Collaboration, Communication; Rhetorics, Realities
}

Leah Knight and Alison Mark

What follows are the results of an experiment across the boundary between the humanities and the sciences. This article transcribes (in edited form) correspondence exchanged between the authors as scholars working at two comprehensive research universities, with student populations of approximately 18,000 and 30,000, in Ontario, Canada. At the time of the exchange, Alison Mark was a research associate using her doctorate in materials engineering to interpret what she sees through electron microscopes; Leah Knight is a scholar of English literature who studies the textual remains of early modernity. Despite being lifelong friends, we have never worked to bridge the apparent chasm between our disciplinary turfs. ${ }^{1}$ In our first steps toward such a collaboration, which we present as a tentative model for similar endeavours, we explore that postulated gap, establish its contours, and reflect on what our travels through our correspondence have shown. If one aim of ScienceHumanities is to reassess how we might interrogate and re-conceptualize disciplinary boundaries in the production of knowledge, this article offers a case in point by examining those matters in relation to two individual producers. We hope through this groundwork to advance the larger conversation about how cross-disciplinary collaborations might play out in future.

\section{Reflections on context and method}

The thinking and procedures that led to this article were stimulated by the 2016 ScienceHumanities colloquium in Cardiff, where Knight acted as a respondent to the proceedings. Back on home turf, she continued some threads of the conversations begun there - among delegates who were, almost without exception, practicing humanities scholars rather than scientists - with Mark, whose perspective as a scientist she valued. We decided to formalize this conversation in a way we hoped might be valuable to others interested in enriching the ScienceHumanities, not least through conversations between scientists and humanists. We thus separately compiled and then exchanged questions about each other's disciplinary experiences; after drafting answers, we also answered our own questions (as if they had been asked of us), since we felt those answers would reveal more (to us, and others) about our own disciplinary habits, structures, and challenges.

Some of the answers produced were surprising, and some confirmed expectations, but two unexpected facts about this process stood out. First, our questions - as well as the way we structured them, rhetorically - differed considerably, and in ways almost stereotypical of our disciplines. That is, the humanist asked about people: what humanists and scientists think about or how they value one another; the scientist's questions, in contrast, were largely technical and impersonal. From the outset, then, our ways of thinking about this conversation were shaped by our training.

A second unexpected finding: we were each distinctly nervous about exposing our responses. If even friends found such an exchange nerve-wracking, that might 
suggest why few engage in such cross-disciplinary work: it feels fraught with risk which could not, in this case, be personal, and so must be professional. Like our questions, that risk varied by discipline: the humanist's uncertainty was based on her interiorization of the relative cultural inferiority of the humanities. She felt questions delving into their heart, poking at what made them tick, might betray vulnerabilities in something she held dear, and feared her answers might confirm or deepen what she perceived as the widespread presumption that the humanities lack value - at least in terms of data, method, or novelty worth the name - a presumption she worried was particularly bred into scientific bones. The scientist's discomfort, in contrast, derived in part from speaking for the sciences when she - a research associate in an internationally vital laboratory, but not a tenure-track professor - did not quite consider herself, or consider herself considered, a fully-fledged member of that tribe. Of course, an institutional outlier might be more perceptive than someone fully absorbed into the rules and roles imposed by insider status; but the precarity of that position might also make her less free to articulate that perspective safely.

We began by asking Mark to answer the questions that Knight had composed for her.

\section{A scientist answers a humanist's questions}

1. What do scientists (generally) think of the humanities? (Do they think of the humanities?)

I would say scientists don't think about the humanities often. Opportunities to mix in an intellectual environment - such as, for instance, at the university itself - rarely occur, and scientists in general do not seek them out. The closest exceptions are when scientists are interested in education or outreach.

That does not stop scientists from sometimes making generalized disparaging remarks about the humanities. But more often scientists turn on what are seen as the soft sciences (e.g., psychology); they are just a little threatening, and so must be put down. Scientists think of humanities as easy, probably not very useful, but not threatening; inoffensive, nice to have around but very removed from day-to-day life and work.

\section{What do scientists think of humanist practitioners? (Pull no punches.)}

They just don't think about them much.

I don't think scientists know what humanities researchers do. An average scientist thinks that, because they have read a few works of literature, they know something about the humanities; but, if a scientist were asked what a literature professor does each day, they would say: read? They would not know the process, methods, challenges - anything really. They would probably be a bit mystified dealing with an unfamiliar humanities researcher. They wouldn't know what to say; there would be a language barrier.

[Interjection from humanist:] I agree about the language barrier, both in our publications, where discipline-specific jargon can be unavoidable or valuable, and in more casual interactions. I'm not sure humanists come off better, either; scientists - probably because they spend lots of time seeking grants and thus articulating the stakes of their work - often excel at the socalled elevator-pitch version of their research. Most can sum up what they do and why it matters quickly and persuasively, in ordinary language citing 
common values; humanists, being (often rightly) suspicious of such values, tie themselves in knots.

3. What do scientists think humanists think of them? (Again: is this a thought they'd bother having?)

Scientists want their work to be useful, mostly, and thus at least somewhat understood and accepted. They want society to think they are doing valuable work. They like prestige. They probably recognize that some humanists might think, like society does, that some projects are too esoteric and a waste of money. A self-aware scientist would likely realize a humanist might think scientists are arrogant. He probably wouldn't care.

4. We've studied and worked in our fields for a couple of decades: do you perceive a change in relations between humanities and sciences in that time? If so, what, and what do you think has motivated it?

Science has come into the news and public sphere more as our careers progressed; this has highlighted both its positives and negatives, and unjustifiably put science onto a pedestal and into a box. Science has unhelpfully become this isolated, special thing.

To me it seems the humanities have been stable: relative to science perhaps losing out on attention and funding, but it does not seem that their prestige has altered. (These mentions of prestige are probably revelatory: prestige is important to scientists at least.)

Scientists have perhaps become even more focused and thus less likely to think about humanities or attend events where they might meet humanists - even though scientists are also pushed to be more in touch with society and communicate more. But they don't connect much with the humanities; instead, they turn to visual or dramatic arts, media, and communications experts.

5. Could there be social or cultural benefits generally to greater interaction between scientists and humanists?

Yes! But I don't think such interactions have to be scripted. If all academics had more time to do non-work things, with full social lives involving people outside their conference circuit, it would encourage interaction between disciplines: ideas would naturally be shared and different perspectives seen. This would help mutual understanding and affect work in subtle ways. It might contribute to changes in attitude in academics, which non-academics might appreciate.

6. Is the problem of incompatible methods what prevents significant collaboration between humanists and scientists?

I don't think scientists really know what methods humanists use. But the problem of data is difficult to get over - and the ideas of testable hypotheses, repeatability, and quantified uncertainty. Exploring how these issues could be addressed in a humanities-science collaboration would require both sides to see things they take for granted differently, which seems valuable.

7. I see room for meaningful collaborations between historians or philosophers of science and active scientists, but have more trouble seeing room for scholars of literature and scientists. I wonder if this has to do with the object of history, philosophy, and science being something identifiable as reality (however problematic a term), where scholars of literature primarily study representations, a habit of mind 
harder to reconcile with what scientists do - although they often work with models and diagrams which are, in effect, representations ...

There is also room for study of the use and mis-use of supposedly specific language by scientists in their publications, and for collaboration in a study of the ways researchers move from evidence to story. Even if some researchers might object to the word story, a narrative is always there in some form.

8. Before this conversation, you mentioned your interest in collaborating with a humanist: what led you to that interest, and what did you think someone outside science would bring to the occasion?

I think often about how science is portrayed as other and unitary. Science is many things, and more part of people's everyday experience than is generally discussed, so science does not deserve its pedestal. Data obtained by experts is more valuable than non-expert opinions, but science itself is not a magical force or a religion. I would like to show how science fits into life, society, and other forms of study more than it is portrayed as doing. And getting various people's thoughts on a subject can reveal new ideas and perspectives, even unintentionally. Researchers should always be open to new ideas and perspectives. Scientists can be hidebound and too sure of themselves.

[Interjection from humanist:] We humanists are not immune to hidebinding! But since I've always admired the skepticism at the heart of the scientific method, I've been puzzled by its absence when I meet grandstanding scientists. That seems incompatible with the intellectual method most crucial to the discipline. Some of this excessive certainty appears driven by the need to accrue funds: a researcher must tout his wares, and can hardly do that skeptically. Ever met a skeptical salesman?

9. Something unmentioned thus far: we're both female. I'm female in a more traditionally and currently female-tolerant discipline - although its femaleness is a relatively new factor, and much less the case than I think many people assume whereas you're in a field (engineering science) almost doubly masculine in orientation. Is there any role for gender in this conversation?

I think the fact that we are having it is a result of our femaleness.

Many scientists think the way to be the best scientist is to focus on a research problem to the exclusion of all else; anything else is soft, a waste of time, simply boring. Some do see value in doing other things, but proportionally more women are open to outside-the-lab activities.

10. A relatively new factor skewing our relationship with science, and possibly ourselves, for the worse, is the pressure for humanities research to be funded more. That is, research appears valued more if it costs more. This affects the projects people choose - and means more of us are going after smaller slices of the same pie, while needing more calories just to survive. Humanists feel this is an import from the scientific model, where a successful lab is an expensive one, owing to the cost of specialized equipment and the tendency for a productive lab to grow in personnel. What do you think about this?

I imagined humanities researchers wanted money to travel to sources otherwise unavailable, or to go to a conference; it never would have occurred to me that funds led to prestige in themselves. 
In science, the ability to get funds implies a strong researcher (often inaccurately), and lots of highly valued research is expensive. But just because a project cost a lot does not give the project more perceived scientific merit.

A weakness in the science funders and community is following up on results of funding. You would think a researcher who won a lot of money might lose prestige if they did not follow up with decent research; generally, though, as long as the researcher does not totally waste it or do something fraudulent, they retain the prestige of winning money even if they do nothing spectacular. Thus, funding can pile up on certain star researchers, because, as well as prestige, money brings equipment, which brings graduate students, which brings papers, which brings more money.

\section{A humanist answers a scientist's questions}

\section{What characterizes or defines a contribution to the field?}

Such a basic question suggests the humanities are a total black box to scientists! Or maybe you start with basics because that's the science way? You don't presume; you gather data methodically, where my questions leapt in medias res to the thick of the personal: not "What is X?" but "What do you think about X?"

Already I feel in the weeds, which grow in the shallows, where I fear we humanists belong: peripheral, stumbling through muddy water, tripping on obstacles which are not so formidable but can't be removed entirely, and shouldn't be, either: the ecosystem needs weeds, not least for good habitat - but also good hiding spots: and I worry, sometimes, that the humanities are thus, and this analogy too good, because too revealing! But I also worry that it's only an analogy, and thus meaningless; I've been schooled before by more rigorous folk in how irrelevant resemblance is to what anything actually is, as opposed to what things are like, which is supposed to matter less: perceptions, experiences, and representations, the weedy humanistic domain. And despite worrying about the worthlessness of my analogy as such, I'm also sucked in by it, finding (or making?) patterns as a result: what research method is this? Is this research, or method? Goodness no, you must be saying: by no means or measure that matters to science, anyhow.

[Interjection from scientist]: There is great value in exploring what things are like in natural phenomena; this can be a very good way to understand a newly-observed process. Something we already understand can be a starting point for understanding something new. Models of phenomena in nature often follow common patterns. The same forms of governing equations apply to many processes, so analogy can be very useful in science.

I should still answer your question: "What characterizes or defines a contribution to the field?" If you are asking about the humanities as a field: it isn't. It's superbly plural, featuring not altogether contiguous fields but a patchwork interspersed with topographical obstacles (natural and human-made) preventing workers in different fields from always seeing eye to eye.

Even within literary studies, a contribution can be many things. To retreat, momentarily, to the objective simplicity of the material form: it might be a journal article or conference presentation or bound book; but that book could be a monograph, an edited collection, or even a work of literature. Now there's a blurring unavailable in science: where the humanities can study art (among other things) or create it, scientists only study nature. But then, Dolly the cloned sheep must be a line item on someone's CV, just like the synthetic hormones I take; so of course science is 
as creative as the humanities. It took this conversation to make me realize that as a parallel, not a difference.

2. How do researchers decide what to research? What are the criteria for judging whether a work should be published or a project funded?

How people select research topics can be pretty ad hoc, at least at first: you take a course on $\mathrm{X}$ text or $\mathrm{Y}$ theory or featuring $\mathrm{Z}$ issue; you're interested in pursuing it further, or become convinced you have something special to say on the topic; or, in literature, you read Text A, which leads to Texts B-K, when you have an epiphany interrelating them. But other people probably start the other way: interested in $\mathrm{Z}$ issue, they work back through Theory Y to Text, Artifact, or Phenomenon X. You either start with a particular material or approach: if a material, you come up with an approach to reveal more about it; if an approach, you find materials to apply it to.

As to criteria for publication and funding research: my own reviews of peers involve an acquired gut instinct for what is responsible work that moves the conversation forward; what I write up in response to the publisher/granter's criteria is an attempt to articulate that instinct in terms they will respect.

Incidentally, the Social Sciences and Humanities Research Council of Canada (SSHRCC), the main source of humanities funding in Canada, has (or used to have everything is always changing) a category of response to applications called 4A, signifying, "This project is worth funding, but we're out of cash." It's even used on people's CVs as a (local) source of credibility: "My project is worth doing; I just can't afford to do it."

\section{What is data? Is data a useful concept? Can one think in terms of data versus} analysis?

If data means "what is given," what's given in literary studies is some version of text: a book, poem, or other graphic unit, conventionally, or some other cultural artifact or phenomenon which is treated, by various theoretical means, as similarly legible.

Also taken as given is some degree of historical context and circumstances. That is, the notion of treating cultural artifacts as free-standing is an impossibility now (not once upon a time), which might be why humanists feel skepticism about or alienation from the concept of data, which claims a space for itself as a text free from context, circumstance, and contingency.

In much humanities work, forms of theory are treated as data; perhaps because my first introduction to theory was in the sciences, and I first understood that the thing to do with a theory was to try to falsify it, I often find this approach problematic.

Humanists can think in terms of data versus analysis, but are more likely to refer to description versus interpretation: generally, you must describe what you're looking at (and set parameters on it) before interpreting its meaning. In many fields we do not, however, put a lot of stock in keeping the two categories widely separated.

\section{Is novelty (of data, of analysis) an important concept? How is it defined and achieved?}

There is some sense of cumulative understanding being reached, but not straightforwardly or over the centuries. Many humanists are suspicious of unitary cultural progress; yet there is an incompatible sense, often among the same scholars, that our most recent times are the only ones not completely benighted. I suppose that suggests a form of importance for a form of novelty. 
In an appropriately open-minded institutional context (an endangered species), novelty could be perhaps defined as something that changes how we regard a phenomenon (in literary studies: text, period, author, genre, material practice). Our way of finding novelty is rarely as definitive as a whodunnit, at least about anything that matters. Discovering an author's birthday was 10 years earlier than previously thought is definitive, but of minimal impact compared to a new way of interpreting that author's work. Generally, the goods in humanities are in analysis, not data. A novel way of understanding can come from setting a thing in a context in which it has never appeared: newfound historical circumstances, or the theories I mentioned above, or even the worldview of the current reader. That last might be the kind of work most conventionally associated with a literary scholar, but such one-to-one, reader-to-text interaction is not much valued in itself now: it must be bolstered by something larger.

My sense that novel analysis is more valued than novel data might be driven by my subfield: much early modern territory is well trod, so innovative analysis is simply more available than unstudied data. But most humanities scholars work on contemporary phenomena - newly published novels, new genres like food blogs - so fresh data is almost too given! Since it is obviously already present, what it needs is understanding. Even with contemporary materials, then, although novel data is involved, analysis prevails.

\section{Does collaboration happen? How? How is the work divided?}

Collaboration does happen, and increasingly: small, where two professors with common interests write a paper together, and large, where an impresario with a multimillion-dollar grant wrangles a team of scholars over several years. But many humanists perceive collaboration as being pushed by people with a narrowly scientistic model of scholarship who fail to note that we are not funded like scientists, which affects collaboration's viability. Those using this model also do not seem to consider that much of our work must happen in our heads, and that the model of a single author can work well.

On dividing labour: when collaborating, I have often found the mere communication of visions challenging - which is funny, because literary scholars are presumed to be pretty good with words. But since we usually work alone, the habits and skills for collaborating are unfamiliar. I'd like to know how scientists learn to collaborate: from a manual? on the job? This is one thing the humanities could stand to learn from science.

\section{How is a research project structured? Is there a question to be answered? How do you know when a project is finished?}

I've realized why I panicked at your first question: it felt like a test where I don't have the answer; I now see this was because there is no single answer to most of these. A project can be structured around an edition: take a text or several and represent, annotate, introduce, and compare it or them with related material to arrive at a meaningful sense of it and its context. Or take a topic and write, in a few chapters, enough new stuff to support a thesis you put forward: that's a monograph. There is the journal article, like a chapter from a monograph, and sometimes a first draft of one. There are digital initiatives, although no pre-publication mechanism is yet in place for peer review. There is what is called practitioner research: the production of a poem or a symphony. I'm not sure how it can be research: what is being searched again, to push the etymology? But it seems clear that scientific creative work like this is done 
and does count - again: Dolly! - so perhaps humanists might learn from scientists how to construe such work as equally viable and valuable, in institutions where it is not treated as such.

You ask if there is a research question to be answered: things are not always that direct in the humanities, possibly because, without the narrowing pressure (meant approvingly, here) of the experimental method, we don't need to be as precise about what we set out to discover; we just set out, see what we see, and account for it. It is often quite exploratory, though we sometimes pretend otherwise or feel pressured to (this time, I refer to bad pressure exerted by narrow minds who see some bastardized scientism as the only valid way to learn) - so you will see people make really overt rhetorical moves, sweating out questions that are bloated versions of what they actually wonder.

It's not that we don't wonder things we could phrase as questions; it's just that the wonderment often leads somewhere else than predicted, and that digressive tendency can be productive. Virginia Woolf describes this, in A Room of One's Own, in relation to her own creative thought process - which is evidently her critical process too, since she uses it in writing ground-breaking lectures on women and fiction. She contrasts thought which is like letting down a line in a murky river letting it drift, waiting for a nibble, patient with the inability to see beneath the surface - with the excavation of hard, nugget-like truths set, trophy-like, on the mantel for all time (Woolf, 4-7). Fish eventually decompose; similarly, Woolf's thoughts might age, but they also have the potential to reproduce and sustain other life forms, unlike rotproof but non-renewable nuggets. She is contrasting masculine and feminine modes of thinking, or institutional (Oxbridge) and personal ones; but could this contrast also handily caricature humanities and science thinking - if only to provoke disagreement?

We don't tend to build in a mechanism for knowing when a project is finished - which is probably why we take longer to finish than we wish! Perhaps we could benefit from more parameters: "In this project, I will consider X, Y, and Z and then be done." That would likely yield more negative results, of the sort that fail to find publishers in science - and I suppose we all have the humanities equivalent on file, allegedly half-finished projects which will never end. But we do tend to feel that just reading the next book, or consulting one more source, will take us to the promised land. This is one trouble with the exploratory approach, or Woolf's fishing line: even after hours with no bites, you could always sit longer. Sometimes I long for more nuggets, with their distinct edges, easily seen from afar.

\section{What are the external pressures from the funding bodies? From society? (Are there any?) Have they changed recently?}

The pressures have increased of late; the change may have started around the turn of this century. I recall an article by a history professor I admired who wrote an editorial querying the shift in funds offered (by SSHRCC) away from small projects toward large programs. This meant that if you learned, halfway through a paper, that you needed to visit a particular archive to finish, you couldn't get a grant for that; instead, you had to predict in advance the very things you needed money to find out. Yet expenses in the humanities once legitimately arose piecemeal, and were taken care of accordingly: infrequent, irregular, and small amounts made sense in many projects. Such projects might not have a through-line to every other thing the researcher did, which was acceptable. (That same professor, as a case in point, wrote books on early modern games, nuclear disarmament, and English pigs.) But there has since arisen a desire to professionalize humanities outputs, and a professional veneer has been 
sought through greater regularization. That has led to at least the appearance of greater specialization, which gains respectability from the fact that, in science, a narrow focus tends to be required by the sheer cost of the equipment involved (plus the rarefied training to use it). The pressure to professionalize and produce more regular and specialized (and so often scientistic, if not scientific) research summarizes the pressures exerted by funding bodies, which derive ultimately from society, I suppose.

Next we answered our own questions, partly to clarify why we had asked them. In this next round, a humanist reveals why she is preoccupied with the relative valuations academic workers place on their work, and a scientist explains her focus on technical definitions of units of, and approaches to, the work.

While Mark's questions, in fine scientific fashion, were perfectly replicable when fired back at her, some of Knight's (typical humanist?) required fine-tuning to address the different subject positions involved. She edited her questions as indicated below. For brevity, questions are combined where possible.

\section{A humanist's questions, answered by herself, for a scientist's information}

1. What do scientists humanists (generally) think of the humanities sciences? (Do they think of the humanities sciences?) 2. What do scientists humanists think of-humanist scientist practitioners? 3. What do scientists humanists think humanists scientists think of them?

Most humanists suspect most scientists consider the humanities inferior in method if not matter. We perceive ourselves treated by scientists as pets, kept around because we're (as you suggest) harmless, generally nice, and occasionally entertaining - also handy for proofreading! - but also because it's understood that a university needs the arts, a bit at least, if ideally in the worst offices and crappiest teaching slots.

That said, I feel there is an unnecessary gulf between real live scholars in humanities and science, even though we work on the same campuses, are supported by the same associations, serve the same committees, and share many concerns about day-to-day working conditions, the changing nature of the institution, and how societal support for and understanding of intellectual work appears to be diminishing. Faculty governance is one way to get both humanists and scientists in the room as equals - but its weakening is also one way in which support for intellectual work has diminished in the past generation - perhaps less in society than, more insidiously, the university itself.

That is to avoid the question, probably because I'm uncomfortable with my answer: many humanities scholars, safe among their own, speak resentfully of the sciences, although not of specific colleagues (whom they tend not to know). I feel this attitude is born of xenophobia combined with an inferiority complex.

I went through school with wonderful friends in various sciences; although I was confused, as an undergraduate, as to why they predicted I would soon serve them at the drive-thru on their way to well-paying jobs, I took this as good-natured ribbing, which it was, and not evidence of entrenched superiorism, which I guess (you suggest) it also was. But I also felt many science-oriented people were some of the humblest, most humane and tolerant people I knew, while I met at least as many closed-minded humanities types who built a claimed superiority on a platform of ignorance or fear of what they dismissed: science. 
In sum: while some humanists think well, if not uncritically, of scientists, few would consider the way scientists work superior - although I think many secretly fear it is.

4. We've studied and worked in our fields for a couple of decades: do you perceive a change in relations between humanities and sciences during that time? If so, what, and what do you think has motivated it?

As in many cultural arenas, polarization has been at play: the twain find it harder to meet in scholarship as in politics. Some of this probably relates to increased time- and productivity-pressures felt by faculty owing to the university's corporatization; as you imply, there are fewer opportunities to get together (so it seems when I read narratives of scholars of yore). That is partly owing to the flip in the ratio of full-time to parttime faculty: something like $75 \%$ to $25 \%$ in the 1970 s, now in many places the opposite. To make ends meet, part-timers rush between campuses, generally without an office to perch in, and not invited (or, if invited, unavailable) to join the university's broader culture of research, service, and society. Full-timers are similarly pressured: with a lower proportion of faculty contributing to governance, we are all stretched thinner. Because we don't get together, except to rush between meetings, we don't realize how much we suffer in common across a disciplinary gap that is pretty bridgeable - if we had time to walk to the edge, see what's there, and start building.

5. Could there be social or cultural benefits generally to greater interaction between working scientists and humanists? If so, what kind?

Yes, many: largely to do with the restoration of the university as a unique and valuable cultural institution, which is being badly compromised. On a more quotidian level, we could share working methods. I would love to learn how a lab is run, or how it is possible to write a paper with six authors: the very mechanics of such scientific practices baffle humanists.

I often wonder if scientists have enough room in their discipline for metadisciplinary reflection, as is very common (perhaps too common!) in the humanities. Perhaps that is something scientists stand to gain by spending more time with us.

[Interjection from scientist]: I think scientists these days are tied up in worrying about and fighting for funding; I don't think they think as much (or at all) about the role and future of the university as an institution.

\section{Is the problem of incompatible methods a fundamental one that prevents significant} collaboration between humanists and scientists?

Our methods need not be incompatible, but often are. Some scientists could do more reflective work on their work as humans, and consider the role of their subjectivity in what they do - and many humanists could benefit from articulating why their methods are rigorous enough in their treatment of evidence and reasoning to arrive at compelling claims, arguments, and theories. But as long as we remain suspicious of opening our home disciplines to outsiders - as long as we feel we are ceding ground through methodological interdisciplinarity - we will not get past the perception of incompatibility. But incompatibility is often an excuse when a host of other factors make people turn away from each other pre-emptively.

7. I see room for meaningful collaborations between historians or philosophers of science and active scientists, but have more trouble seeing room for scholars of 
literature and scientists. I wonder if this has to do with the object of history, philosophy, and science being something identifiable as reality (however problematic a term), where scholars of literature primarily study representations, a habit of mind harder to reconcile with what scientists do - although they often work with models and diagrams which are, in effect, representations ...

Since my perception is built into the question, I will respond to your answer: you suggest there is room "for collaboration in a study of the ways researchers move from evidence to story." I can also see a first-year undergraduate course, or interdisciplinary graduate course, called From Evidence to Story: Scholarly Methods, designed to ensure students understand how their intellectual work (and that of the world) actually works, how it fits into the larger project - historically differentiated, disciplinarily diffuse - of epistemology, and why it matters to consider ways of knowing rather than rushing to proclaim what we know.

Although my question framed literature as the worst subject for such an interaction, your answer, foregrounding "story," reminded me I chose literature as my discipline based on a sneaky sense that I could study everything under that guise since, as you say, story is always "there [everywhere!] in some form." But it's not just narrative that's present in every human-made account: figuration is equally influential. My understanding of figuration derives from metaphor, where a scientist might understand it from models, schema, or heuristics; either way, we again have a framework for meaningful collaboration.

9. Something unmentioned thus far: we're both female. I'm female in a more traditionally and currently female-tolerant discipline - although its femaleness is a relatively new factor, and much less the case than I think many people assume whereas you're in a field (engineering science) almost doubly masculine in orientation. Is there any role for gender in this conversation?

I was bowled over by your answer: "the fact that we are having [this conversation] is a result of our femaleness." That would never have occurred to me - likely because of our disciplinary difference. Unlike you, I know many men in the humanities having similar conversations. It fascinates me that you see gender as so much more divisive in the sciences, and that scientists would see this work as "soft." That's a metaphor you used more than once as one scientists use to criticize something, and of course such metaphors have their own gender dynamics: the harder sciences are of course better in a man-made hall of mirrors with only male anatomy reflected back. People often mistakenly think you can only build (upward, of course: erecter yet with your erector set) with hard things; that's the clearest, because bluntest, understanding. So scientific discourse becomes valued for a bluntness derived from hardness derived from masculinism (or, historically, patriarchy: pick your poison), while humanities writing is mocked for a feminized (and thus doubly mocked) softness: a diffuse quality crucial to its recognition of, tolerance for, and even cultivation of ambiguity and polysemy (with this last easily tarred, in such sexualized rhetoric, as a kind of intellectual infidelity or promiscuity). But you can actually build amazing stuff with softness: living cells, for instance, are pretty squishy, remarkably permeable, and thus open to change and exchange - and stronger and more functional for it. So it often seems a failure of the imagination to fall back on these binaries: hard or soft as inherently better or more valuable, like male or female. We all have our uses and limits, we must know. What we forget is that such failures of imagination have real effects in our often unduly hard world. 
I don't think the humanities should renounce its association, however halfcocked (that's from guns - but all the same) with the feminine. One way for the humanities to become stronger - in their self-perception, and the eyes of others - is through a feminist-inflected discourse that recognizes the value of our difference as such, as the often marginalized or underdog figure in life's (and the academy's) inevitable, but not immutable, either/or.

\section{A scientist's questions, answered by herself, for a humanist's information}

1. What characterizes or defines a contribution to the field?

A discovery of a mechanism, an explanation for a behaviour; the invention of a new thing; the discovery of a new property; the discovery (or verification) of a new thing.

[Interjection from humanist]: These translate to the humanities: "a discovery of a mechanism" works if we imagine "mechanism" as a metaphor for a human or cultural happening; "an explanation for a behaviour" is easy, since disciplines like history and cultural studies explain past and present behaviours (although these are generally construed as events, periods, discourses and so on); "the invention of a new thing" is parallel with creating a work of art or argument; "the discovery of a new property" is done all the time - in literature, new facets of texts are found by new ways of reading; and there are parallels in archival finds with "the discovery (or verification) of a new thing."

The lines between the exploratory methods of the humanities and the rigorous methods of scientists blur more than one might think, given their representation in media coverage. Scientists don't disabuse people of the idea that all science follows the hypothesis-test-result path - but it doesn't (or at least it is often very un-rigorous). Plenty of science gets done by people who start down a path looking for $\mathrm{X}$, on the way see $\mathrm{A}$ and $\mathrm{B}$ and $\mathrm{C}$, and end up investigating those. In biology there is a recognized distinction between exploratory and hypothesis-driven research; in other fields it is less often or more quietly discussed. Hard and fast rules about method exist where needed: in drug creation and disease research, where life is on the line. In other areas, methods are more flexible. This is not to say that honesty and ethics are not important; it's just that it is acceptable not to know exactly where you are going when you start.

[Interjection from humanist]: This makes things seem much more openminded than I had thought; but the fact that this has to be kept quiet seems strange.

Professing to Learn, a recent book on how mid-career scholars sustain themselves through continuous learning, includes accounts of the process you describe: noodling about, following an unexpected or covert inquiry, then seeing it pan out in surprising ways (Neumann, 65-7). This is what Woolf valorizes with her fishing line drifting unseen underwater.

\section{How do researchers decide what to research? What are the criteria for judging} whether a work should be published or a project funded?

Novelty is always the hyped factor: show us something new and exciting. This is an area of discussion in the sciences now: if only novel research is funded and published, how do we verify reproducibility, which we claim to value? 
More practically, researchers do follow the paths you suggest: by starting "with a particular material or approach." A researcher might be expert on or interested in a thing and look for ways to learn new things about it, or they might be expert or interested in a technique and look for new things to do with it.

External pressures exist: research is driven by funders to be demonstrably applicable to problems seen by general society (and widely communicating the results is given more and more importance). Scientists regularly joke about funding buzz words: currently, nano, enviro, green energy, and biocompatible. One in your proposal title increases your chances of getting funded.

A scientific contribution is a paper in a peer-reviewed journal: that is the contribution. Scientists also write books, patents, software, and conference papers, but these are secondary; and despite how often their importance is discussed, outreach efforts are not valued highly by tenure committees and funding bodies. To get money, you must say you will do outreach; but doing lots of outreach will not get you more money.

Criteria for judging whether a work gets published are novelty, contribution to field, reproducibility, correct and proper experimental method, and data analysis. Factors such as trendiness and how exciting the research is matter too. It matters how well you have told your story.

\section{What is data? Is data a useful concept? Can one think in terms of data versus analysis?}

Data is numbers, images, facts, observations: in theory, it is totally objective. Analysis is what you do to data to help it say something interesting. In a paper, these are reported separately, but the dividing line is harder to maintain than might be thought. In the process of analyzing data, you often create more numbers and images: are these now data also?

[Interjection from humanist]: As mentioned, the humanities are not highly oriented, or trained, to separate data from analysis, or to believe doing so is possible. Some disciplines do separate them: traditional art history often features extensive descriptions of objects studied, not least because it can be otherwise impossible to convey their nature. Some kinds of history involve precise separation of huge data sets from analysis. Some philosophers aim to be quite clear about such things. In my field, aspects of book history and digitally-empowered distant reading certainly rely on data and statistical analyses; but elsewhere in literary studies, data/analysis relations are often a mess - perhaps because we primarily use words on words, with our analytical tools of no higher epistemological order than what we analyze, as in Escher's self-drawing hands. That said, Escher's hands present a wholly original and powerful vision: would we be better off without?

\section{Is novelty (of data, of analysis) an important concept? How is it defined and achieved?}

Novelty of data, if well-explained, is probably more highly valued than novelty in method; but novel data with no explanation of what it means or where it comes from is second class.

The pitfalls of the constant pressure for novelty are being recognized: good but not flashy science does not get published, so reproducibility suffers, because results are not tested, and negative findings are put in a cupboard. Changes toward open 
access, data sharing, and paper repositories will lead to greater publication (or recognized sharing) of work that is not novelty-driven if they reduce the power of the big journals (as is predicted) and are enforced as the new norm for scientists. But the strongest incentives remain to publish novel work.

\section{Does collaboration happen? How? How is the work divided?}

It is difficult to be a lone scientist, and thus unusual; collaboration is taken for granted. A single-author publication is usually a short comment on a narrow topic, not requiring much or any experimental data, or a review of a trendy topic. In both cases, they are usually written by an established researcher. Because they are rare, and it is considered that not just anyone can get one published, they do have a certain cachet.

[Interjection from humanist]: This difference explains so much about our intellectual cultures, and why people in each field are suspicious of each other. It's as if you had a culture where people live in communes and one where they live in nuclear families: each thinks, "How can you live like that?"

Collaboration is most often between one driving researcher $(\mathrm{a} \mathrm{PhD}$ student, a post-doc), a supervisor, and people who contribute either specific techniqueknowledge or specific interpretation-experience. The driving person or supervisor runs the project (depending on the experience of the driving person) and the driving person is the main author. Generally the driving person is the one whose degree/career most depends on getting the project done. Writing is almost always done by the driving person, with paragraphs or sections by others, and everybody getting a say in editing before submission. But I have also been part of projects with two sides: I gave data to another, they gave data to me, and in the end we each wrote papers focusing on our own side, with input from the other side. An example would be a project with an experimental side (physical tests on a material) and a modeling side (computational models of material behaviour), using the other's data with the results written up for different audiences.

6. How is a research project structured? Is there a question to be answered? How do you know when a research project is finished?

Scientists have been quite successful in presenting themselves as logical and organized. In reality, they are mostly just as hodge-podge and prone to side-tracks and vulnerable to curiosity as anyone. It is a well-known joke that every time you do just one more test to answer X question, you end up with more questions. Even if you start with a clear question, you rarely get a clear answer. There are always uncertainties, and it can be hard to know when to stop trying to make those uncertainties smaller.

So a project is structured to answer a question, although it can be quite a vague question. You usually have a method in mind to answer the question and thus a plan of how to proceed. In my field, it is likely you will change your approach, adding tests as you see what your initial investigations reveal. It is important that, when you are done, you can describe what you did so as to allow someone else to do it and see what you saw.

7. What are the external pressures from the funding bodies? From society? (Are there any?) Have they changed recently? 
For science, they have changed since I started. Outreach used to be the realm of public relations, science-camp counselors, and a few interested scientists. Now it is pushed on everyone, often only reluctantly accepted, and done minimally to meet grant requirements.

Socially relevant research is now strongly promoted, but this is more a new term than a new concept. There has always been a perceived separation between applied and pure research; many funding bodies have long connected applied research with faster return on investment. The current push for socially relevant research matches a wider push for higher and more certain investment returns. Other manifestations of this trend include more reporting requirements by grant holders and requirements for statements describing research impact.

Open science is definitely new since I started my career. The idea that data and papers should be accessible for the better advancement of science and service of the public is becoming well-accepted, but the incentives and mechanisms lag behind.

\section{Conclusions}

Our correspondence highlighted how, outside our distinctive materials and methods, scientists and humanists have many common concerns, problems, influences, and driving forces. We mentally approach research in similar ways, asking: What are we curious about? What do we already know? How can we build on that to create something new with value? In both cases, the value sought and found is influenced, for better and worse, by funding and publication pressures. There are also clearly differences in culture: humanists generally work alone, where scientists collaborate; humanists engage in more personal and institutional self-reflection than scientists do. But the largest difference is practical: in science, there are experiments, expensive equipment, and measurements resulting in quantified observations; in the humanities, there are texts and images, theories and narratives, works of art and argumentation, while the equipment is often the mind, and observations are generally qualitative (although some disciplines, like archaeology and art conservation, are more equipment-reliant and quantitative than average). Despite these differences, there are valuable avenues for collaborative exploration and ways that scientists and humanists can benefit from each other. Below we summarize what we were surprised to learn about what our disciplines had in common and the unexpected differences our correspondence revealed. We close by listing eight points of contact to aid further collaboration.

\section{Surprising commonalities of the humanities and sciences:}

Mark: Finding patterns and working with analogies is an area where we have more in common than I realized. I was also surprised to learn money has become so important in the humanities and that they are increasingly expected to follow a science-like funding model with big grants for big projects. Finally, although we both expected the other field would be ahead with digital curation and recognition, it seems neither has figured out how to deal with digital initiatives very well.

Knight: I was surprised how much scientists are pressured to demonstrate the immediate social efficacy of their work; I thought basic research still held great sway. I was happier to learn that our methods are less distinct than rumoured, and that many scientists follow exploratory, imaginative, digressive approaches. We both perceive 
problems in a naive distinction between data and interpretation and see room to critique the fetishizing of novelty above all else: in the sciences, because reproducibility also needs recognition, and in the humanities because the very idea of originality has long been subject to compelling and productive critique. A more modulated set of ideals seems more appropriate to all of our aims.

\section{Unexpected differences between the disciplines:}

Mark: I had not thought much about how humanities researchers work alone most of the time, unlike scientists. I was also surprised to find that humanities researchers do so much work on the present, researching the world (and the university itself) as it is now; my assumption was that their work focused on the past, with perhaps one eye on the current impact.

Knight: First, it seems prestige is sought much more overtly in the sciences; it tends to be pursued only rather shame-facedly in the humanities, which are often critical of such cultural games despite (or because of) our dependence on them. What you say about science offers humanists a sobering warning about how funding pressures might - if transferred uncritically to our domain - increase our own focus on prestige-related productivity, to the detriment of certain key cultural insights derived from and social commitments related to our work. Secondly, I didn't realize the humanities were so mysterious to scientists, which suggests we could trumpet our work more often and clearly for outsiders - who might, however, not actually be that interested in what they don't know about us, which is something else I wouldn't have been so skeptical as to attribute to scientists without your (somewhat disappointing) insight.

\section{Ways in which humanities and sciences could mutually benefit from more interaction:}

(a) The humanities could clarify the poetics and rhetoric of scientific thinking for scientists who want (or realize the need) to intervene in how scientists think about or value their work and themselves as agents (for example, the soft/hard binary).

(b) Similarly, scientists could learn from a half-century of feminist humanities scholarship to recognize the value of soft and adaptable, yet equally tough and essential, intellectual skills and traits.

(c) Science could persuade the humanities to value elements of conventionally scientific methods, such as working collaboratively to share resources, providing more intensive research training to students, and being more explicit about the selection and treatment of data.

(d) Scientists might offer humanists a model for being more overt about the value of their work, not least so it is not such a mystery to outsiders.

(e) Scientists and humanists should work together to figure out how best to review and otherwise value digital initiatives and the data sharing made possible by new technologies.

(f) Universities might offer mandatory courses for students to witness a meeting of minds among academics from different disciplines, teaching their own materials and methods on common concerns such as matter, error, uncertainty, or the process of moving from evidence to story.

(g) Humanists and scientists should articulate and celebrate the values we share related to research, intensive study, and informed knowledge-making: values we sometimes forget are not universally celebrated off-campus, and which are fragile, 
human-made ideas, rather than hard facts we can take for granted. Institutional protection for and cultivation of them is required, however, for them to thrive in an environment where faculty are increasingly forced to compete for a share of scarce cultural and financial resources (prestige and funding). The ScienceHumanities provides an example of one framework for explicitly thinking about the relations between and across our disciplines; without ScienceHumanities, this interview, for one, would not have taken place or been shared with a community of our fellows.

(h) Scientists have many objections to developments within the university which are already being articulated by humanists as part of their intellectual tradition of critiquing cultural authorities. Scientists and humanists could join forces on this front to resist the bureaucratization and monetization of the university as an institution.

\section{Notes}

1. In composing this piece, we encountered a problem that arises when coauthors need to distinguish their personal contributions. In the sciences, first-person pronouns tend to be avoided through the passive voice, but that solution is unhelpful when our distinctive contributions require foregrounding. We have thus chosen to mingle "we" with "Knight" or "Mark," or "humanist" and "scientist," as appropriate. "Humanist," likewise, is adopted to indicate a practitioner in the humanities, even though the term has a complex history and fraught present. The inelegance of these solutions helpfully points up one challenge of speaking across disciplines. 


\section{Works Cited}

Neumann, Anna. Professing to Learn: Creating Tenured Lives and Careers in the American Research University. Johns Hopkins UP, 2009.

Woolf, Virginia. A Room of One's Own. Hogarth Press, 1929. 